\title{
REDES DE APRENDIZAGEM: HISTÓRIAS CRUZADAS ENTRE ESTUDANTES UNIVERSITÁRIOS E PRECEPTORES DA ÁREA DA SAÚDE
}

\author{
HELENA FRAGA-MAIA
}

Universidade do Estado da Bahia

ANA SUELI TEIXEIRA PINHO

Universidade Católica de Salvador

FERNANDA WARKEN ROSA CAMELIER

Universidade do Estado da Bahia

RESUMO O objetivo deste artigo foi apreender as representações de estudantes e preceptores sobre os processos de aprendizagem decorrentes das relações estabelecidas no desenvolvimento do PET-Saúde "Doutores Mirins". A metodologia adotada foi a narrativa (auto)biográfica e a técnica de pesquisa selecionada foi a entrevista narrativa. As narrativas dos estudantes revelaram que o PET-Saúde contribuiu para a construção de sentidos do fazer profissional e do percurso de formação, na interação com colegas de áreas diferentes, potencializando as redes de aprendizagem, à medida que os conhecimentos de um influenciavam os conhecimentos dos outros e amplificavam a compreensão dos cuidados em saúde de modo integrado. Já na perspectiva dos preceptores, as redes de aprendizagem, construídas pelos diferentes sujeitos, favoreceram a produção de novos significados em torno da atenção básica, sendo esses suscitados pela articulação entre teoria e prática. Durante o projeto, estudantes e preceptores revezaram o lugar de ensinar e de aprender. Ao tecer as redes de aprendizagem, os sentimentos de isolamento e receio da crítica deram lugar ao aumento da autoconfiança, à elevação da autoestima e à integração no grupo, fortalecendo o sentimento de solidariedade e respeito mútuo.

Palavras-chave: Redes de aprendizagem. (Auto)biografia. PET-Saúde. Educação em Saúde. 
ABSTRACT LEARNING NETWORKS: INTERSECTING STORIES BETWEEN STUDENTS AND TEACHERS IN THE AREA OF HEALTH

The objective of this article was to understand the representations of students and teachers on the learning processes from relationships established in the development of the PET-Health "Young Doctors" (Educational Program for Health Work in Professional Formation). The methodology used was the (auto) biographic narrative and the selected research technique was the narrative interview. The narratives of the students revealed that the PET-Health contributed towards the construction of the meanings of professional performance and formation process, which were construed in the interaction with colleagues of different areas, optimizing the learning networks, as the knowledge of one influence the knowledge of others and broaden the understanding of healthcare in a comprehensive manner. From the perspective of teachers, the learning networks built by the different subjects, favor the production of new meanings in relation to primary care through the articulation between theory and practice. During the project, students and teachers alternated the place of teaching and of learning. When creating the learning networks, the feelings of isolation and fearfulness of criticism give way to improved self-confidence, increased self-esteem and integration to the group, strengthening the esprit of solidarity and mutual respect.

Keywords: Learning networks. (Auto)biography. PET-Saúde. Health education

\section{RESUMEN REDES DE APRENDIZAJE: HISTORIAS CRUZADAS ENTRE}

\section{ESTUDIANTES Y PRECEPTORES DEL ÁREA DE SALUD}

El objetivo del presente artículo fue comprender las representaciones de estudiantes y preceptores sobre los procesos de aprendizaje decurrentes de las relaciones establecidas en el desarrollo del PET-Saúde (Programa de Educación por el Trabajo para la Salud) "Jóvenes Doctores". La metodología adoptada fue la narrativa (auto) biográfica y la técnica de investigación seleccionada fue la entrevista narrativa. Las narrativas de los estudiantes revelaron que el PET-Saúde contribuyó a la construcción de sentidos del hacer profesional y del recorrido de la formación, que fueron siendo construidos en la interacción con colegas de áreas diferentes, potencializando las redes de aprendizaje en la medida en que los conocimientos de uno influenciaban los conocimientos de otros y amplificaban la com- 
prensión de los cuidados en la salud manera integrada. Ya en la perspectiva de los preceptores, las redes de aprendizaje construidas por diferentes sujetos favorecen la producción de nuevos significados en torno a la atención básica, siendo ellos suscitados por la articulación entre la teoría y la práctica. Durante el proyecto, estudiantes y preceptores revezaron el lugar de enseñar y aprender. Al tejer redes de aprendizaje, los sentimientos de aislamiento y temor a la crítica dieron espacio al aumento de autoconfianza, la elevación de la autoestima y la integración en el grupo, fortaleciendo el sentimiento de solidaridad y respeto mutuo.

Palabras clave: Redes de aprendizaje. (Auto)biografia. PET-Saúde. Educación en Salud.

\section{Introdução}

As universidades públicas frente ao compromisso com as questões sociais têm promovido ações no sentido de triangular o envolvimento acadêmico de estudantes, professores e usuários do sistema de saúde, no intuito de atender as necessidades da comunidade. Essas ações articuladas reafirmam a importância da inserção social dos estudantes de graduação em práticas educativas de saúde pautadas na perspectiva da participação popular, para despertar o senso crítico e promover o diálogo com trabalhadores, usuários e demais atores. Essa estratégia ajuda a identificar e buscar soluções para problemas que emergem de suas vidas (BARRETO et al, 2013; OLIVEIRA et al, 2012).

É com essa intenção que o Ministério da Saúde, por meio da Secretaria de Gestão do Trabalho e da Educação na Saúde (SGTES), em parceria com a Secretaria de Educação Superior (SESU), com o Instituto Nacional de Estudos e Pesquisas Educacionais Anísio Teixeira (INEP), do Ministério da Educação (MEC), e com o apoio da Organização Pan-Americana da Saúde (OPAS) criou o Programa Nacional de Reorientação da Formação Profissional em Saúde (Pró-Saúde). A partir dele, e com a parceria das Instituições de Ensino Superior, promove a integração ensino-serviço, assegu- rando uma abordagem integral do processo saúde-doença, com ênfase na Atenção Básica, promovendo transformações na prestação de serviços à população e nos processos de geração de conhecimentos, ensino e aprendizagem. (BRASIL, 2009).

O Pró-Saúde é uma das propostas adotadas pelas universidades para estreitar vínculos com os serviços públicos de saúde, que nesse contexto são concebidos, ao mesmo tempo, como lócus de formação dos estudantes de graduação e campo de atuação profissional dos preceptores. Com isso, o Programa oportuniza aos sujeitos envolvidos uma maior aproximação, de um lado, com a realidade socioeconômica e sanitária da população, e, de outro, a reflexão do preceptor diante das questões suscitadas pela prática, retomando teorias estudadas na Formação Inicial.

Outra estratégia proposta de inovação pedagógica, que agrega valor aos cursos de graduação da área da saúde, fortalece a prática acadêmica e integra a universidade em atividades de ensino, pesquisa e extensão, a demandas sociais, de forma compartilhada, é o Programa de Educação pelo Trabalho para a Saúde (PET-Saúde). Lançado em 2009, como um norteador da integração ensino-serviço- 
comunidade e da indissociabilidade de ensino, pesquisa e extensão, realiza-se como educação interprofissional. Nesta modalidade, estudantes de diferentes formações, frequentando diversos períodos, em suas graduações, são mediados por professores de várias formações e profissionais de serviços, aprendendo e interagindo em conjunto, com vistas à melhoria da qualidade no cuidado da saúde de pessoas, famílias e comunidades. O Programa valoriza o trabalho em equipe, a integração e as especificidades de cada profissão. Além de atividades periódicas, nos cenários de práticas da rede pública de serviços de saúde, todos os integrantes dos projetos PET-Saúde desenvolvem pesquisa sobre temas prioritários para o Sistema Único de Saúde (SUS) (BRASIL, 2008).

O PRÓ-Saúde, articulado ao PET-Saúde, é desenvolvido nas redes de Atenção à Saúde, com a participação de docentes, estudantes, equipes de Saúde do serviço e usuários do SUS. Estes programas têm possibilitado vivências que ampliam a visão de professores, estudantes e profissionais do serviço sobre o cuidado ao sujeito que adoece, no contexto de sua existência, colaborando para a escuta permeada por dúvidas, encantamentos e descobertas do imprevisível, qualificando a Atenção à Saúde que valoriza a relação entre os seres humanos (BRASIL, 2009).

Por intermédio do Edital (2011) Pro-Saúde/ PET-Saúde do Ministério da Saúde, foi aprovado o projeto "Multiplicadores do Conhecimento: Doutores Mirins e Educação em Saúde destinada a familiares e portadores de Hipertensão Arterial Sistêmica e Diabetes Mellitus residentes no Distrito Sanitário Cabula/Beiru". Este foi pioneiro na Universidade do Estado da Bahia (UNEB), em parceria com a Secretaria Municipal de Saúde de Salvador (SMS). Participaram do projeto uma tutora, docente da UNEB, seis preceptores, profissionais de saúde de nível superior lotados na SMS e doze es- tudantes bolsistas do PET-Saúde. A este grupo foram somados mais oito estudantes, sendo três da Iniciação Científica UNEB e mais cinco voluntários. Deste modo, participaram da intervenção vinte alunos dos cursos de saúde da UNEB, sendo cinco de Medicina, sete de Fisioterapia, cinco de Fonoaudiologia e três de Nutrição.

O projeto "Doutores Mirins" foi idealizado como um conjunto de ações envolvendo pesquisas e extensão em Unidades Básicas de Saúde (UBS), Unidades de Saúde da Família (USF), Centros Sociais Urbanos (CSU) e escolas da rede estadual e municipal de Ensino Fundamental, situadas no território do Distrito Sanitário Cabula-Beiru, no entorno da Universidade do Estado da Bahia (UNEB), de modo a possibilitar o encontro dos estudantes em formação com o contexto da atenção primária e com profissionais de saúde inseridos na assistência, em todo o território. A partir desta interação, os envolvidos vivenciam uma experiência multiprofissional e interdisciplinar, e assim refletem sobre a contribuição de cada ator no processo de melhoria da condição de saúde.

Uma análise do perfil de morbimortalidade no Brasil aponta que dentre as doenças crônico-degenerativas mais prevalentes na população, e com maiores taxas de agravos e óbitos, encontram-se a Hipertensão Arterial Sistêmica (HAS) e o Diabetes Mellitus (DM) (TOSCANO et al, 2008; DUNCAN et al, 2012; CARNEIRO et al, 2012). Em geral, são abordados em conjunto, em função de aspectos comuns a essas patologias, tais como a etiopatogenia, a importância do tratamento não farmacológico, fatores de risco, cronicidade, complicações, surgimento geralmente assintomático, dificil adesão ao tratamento, necessidade de controle rigoroso, para evitar agravos, e de acompanhamento por equipe multidisciplinar, além do fato de que ambas as patologias são de fácil diagnóstico (GUEDES, 2011). 
Dentre os fatores de risco já conhecidos para o desenvolvimento da HAS e do DM, encontram-se os modificáveis e relacionados ao estilo de vida (GUEDES, 2011). Destacam-se a dieta inadequada, com consumo excessivo de sal e açúcares, o tabagismo, o sedentarismo, o alcoolismo, a obesidade, os níveis séricos de colesterol elevado e o alto nível de estresse. Tais fatores têm contribuído para a elevação da taxa de morbimortalidade das doenças cardiovasculares (TOSCANO et al, 2008; DUNCAN et al, 2012; CARNEIRO et al, 2012; PAIVA et al, 2006) que são sensíveis às ações de educação em saúde. Como a hereditariedade também se encontra associada a tais patologias, deve ser considerada como um fator de destaque e nortear ações de promoção de saúde para filhos de hipertensos e diabéticos (GUEDES et al, 2011; PAIVA et al, 2006). Trata-se, portanto, de um cenário preocupante e que justifica intervenções significativas em promoção de saúde, tal como as propostas de educação em saúde como um processo de construção de uma atuação em sintonia com as necessidades sociais da população (BARRETO et al, 2013).

A partir desta constatação, o PET-Saúde, desenvolvido pela UNEB, decidiu enfocar a educação em saúde voltada para a prevenção de DCNT e a promoção de saúde direcionadas à HAS e ao DM. Neste contexto, as práticas educativas em saúde foram concebidas como elementos mediadores do conhecimento científico, produzido nas distintas disciplinas da área de saúde, e a atuação dos profissionais em campo. Deste modo, pretendem interferir e modificar a vida cotidiana das pessoas, à medida que oferecem informações que poderão influenciar na adoção de novos hábitos e condutas de saúde. Além disso, deu-se enfoque às estratégias de articulação do conhecimento prévio com as práticas sociais acerca das doenças em questão, manifestações sistêmicas, aspectos terapêuticos, bem como sobre a importância da adoção de hábitos de vida saudáveis. (COSTA; LOPES, 1996).

O projeto “Doutores Mirins" propôs intervenções de educação em saúde em crianças e adolescentes de 6 a 14 anos de idade, matriculados em escolas públicas da rede municipal e estadual, localizadas no Distrito Sanitário Cabula Beiru, cidade de Salvador, Bahia. Considerou-se como critério de inclusão dos escolares a presença de história familiar de HAS e/ou DM. A presença de qualquer deficiência, quer motora, auditiva ou cognitiva, não foi considerada como um critério de exclusão.

Após a conclusão do projeto, desejou-se cruzar as histórias dos estudantes de graduação com as dos preceptores da área de saúde. Dessa forma, o objetivo deste artigo foi apreender as representações dos sujeitos sobre os processos de aprendizagem decorrentes das relações construídas no decorrer do trabalho. A expectativa foi compreender, do ponto de vista teórico, uma categoria conceitual emergente da pesquisa, ou seja: as redes de aprendizagem.

\section{O percurso metodológico: a abordagem (auto)biográfica e a entrevista narrativa}

As discussões aqui presentes são fruto da análise de sete entrevistas narrativas, sendo quatro com estudantes bolsistas da área de saúde e três com preceptoras. Foi realizada uma entrevista com cada uma das colaboradoras, em março de 2016.

A metodologia adotada foi a narrativa (auto)biográfica e a técnica de pesquisa selecionada foi a entrevista narrativa. Estas foram desenvolvidas a partir da temática relações estabelecidas entre a participação no Projeto "Doutores Mirins" e o seu percurso de formação e atuação profissional. As participantes foram informadas, ainda, de que, durante as entre- 
vistas, não haveria interrupção com perguntas, que elas deveriam narrar livremente e que só no final, quando decidissem interromper, caso fosse necessário, seriam feitas algumas perguntas, a partir do que já havia sido narrado.

A narrativa (auto)biográfica é produzida por um sujeito social que, ao contar suas experiências de vida, "[...] faz referências a diversas pertenças sociais, a uma variedade de instituições: família, escola, trabalho, amigos, bairro de sua moradia, associações" (RHÉAUME, 2009, p. 167). Ou seja, esta narrativa se constitui como uma forma de expressão que é, simultaneamente, pessoal e social.

Assim, o método da narrativa (auto)biográfica, coloca o pesquisador diante da necessidade da escuta sensivel do Outro. Isto se dá por que:

na perspectiva da história de vida, ela também é atravessada pela interlocução que se estabelece entre narrador e pesquisador. A qualidade da escuta, o interesse de escutar, o desejo do sujeito de narrar, o tipo de dinâmica consciente e inconsciente que se desenvolve entre narrador e a equipe de pesquisa vão semear o solo vincular da coconstrução da história. (CARRETEIRO, 2009, p. 131)

Além dessa escuta sensivel, ainda é preciso considerar que o olhar do pesquisador sobre o outro é diferente de como o outro se vê (AMORIM, 2003). Se a narrativa (auto)biográfica é uma síntese de interações sociais entre o entrevistado e o entrevistador, podemos assumir que, nesta relação, não temos um sujeito que conhece e um objeto que é conhecido. 0 observador encontra-se totalmente implicado ao campo do seu objeto. Longe de ser passivo, o objeto modifica continuamente o seu comportamento, em função do comportamento do observador. Nesta perspectiva, o conhecimento não tem o outro como objeto e, sim, a interação recíproca entre o observador e o observado. O conhecimento, portanto, é fruto da intersubjetividade desta interação.
A narrativa (auto)biográfica possibilita extrair as diferentes percepções das experiências temporais dos sujeitos, mas não se confunde com elas. "Através da narrativa, as pessoas lembram o que aconteceu, colocam a experiência em uma sequência, encontram possiveis explicações para isso, e jogam com a cadeia de acontecimentos que constroem a vida individual e social" (JOVCHELOVITCH; BAUER, 2007, p. 91).

A narrativa (auto)biográfica possibilita a compreensão das conjunturas nas quais as práticas sociais se inscrevem, permitindo a identificação de práticas recorrentes adotadas pelos sujeitos. Além disso, preserva perspectivas particulares de uma forma mais autêntica e pode ser detalhada, com enfoque nos acontecimentos e ações.

A identidade narrativa designa tanto o sujeito quanto a comunidade que ele integra, pois a narrativa das histórias de vida revela o entrecruzamento de vivências e pontos de interseção existentes entre eles. Como alerta Souza (2006, p. 145), “o respeito pelas singularidades dos sujeitos, de suas histórias e das suas narrativas são princípios colocados para os sujeitos envolvidos desde o início do trabalho".

Do ponto de vista metodológico, uma das formas de utilização da abordagem (auto)biográfica é a entrevista narrativa, que não se reduz apenas a uma listagem de acontecimentos, mas a uma tentativa de (re)ligá-los, tanto no tempo, quanto no sentido. Este método se constitui como fonte primária, produzida pelo próprio pesquisador, na relação com os outros sujeitos. A entrevista narrativa permite estruturar os acontecimentos em uma história e isto possibilita produzir o enredo, a partir da definição do espaço-tempo que marca o começo e o fim da história.

Entretanto, assumir a narrativa (auto)biográfica como metodologia requer alguns cui- 
dados. Haja vista que a narrativa sofre a influência do contexto em que ocorre, do lugar social que o sujeito ocupa quando narra, para quem narra, em que circunstâncias, com que objetivos (PINHO, 2012). "O quê e o como do que se diz supõem sempre o 'outro' em sua fundamental diversidade" (AMORIM, 2003, p. 11). Cada narrativa é irrepetível, é um acontecimento único.

Uma maneira de interpretação de narrativas, destacada por Bertaux (2010) e aqui adotada, é a chamada análise compreensiva. Imaginação e rigor, segundo ele, é o que estão na base desse tipo de análise, mas se prioriza a primeira. Grosso modo, o processo de imaginação, inicialmente mental e depois discursivo, consiste na possibilidade do pesquisador mobilizar "[...] os recursos interpretativos dos quais dispõe, que lhe ativam o conjunto do espaço cognitivo situado no interior do seu horizonte" (2010, p. 108).

De acordo com Pinho (2012), dentre os indícios que uma narrativa esconde, alguns se destacam e outros ficam, por muito tempo, ocultos. Cada um dos indícios vislumbrados deve ser considerado como a ponta aparente de um grande iceberg. Assim, ao interpretar esses indícios, faz-se necessário inseri-los no próprio contexto do qual fazem parte, levando em consideração todas as suas especificidades, que podem, inclusive, contrastar com a cultura do pesquisador.

\section{Os participantes da pesquisa}

Todos os estudantes universitários entrevistados foram bolsistas do PET-Saúde por dois anos e meio e participaram de todas as etapas de desenvolvimento do projeto, tendo contribuído com a coleta de dados quantitativos, qualitativos, ações de extensão universitária em comunidades e intervenções escolares para a formação dos "Doutores Mirins". Dois deles cursavam Fisioterapia, Lúcia e Sarah,
Clarisse cursava Medicina e Eduardo, Fonoaudiologia. As preceptoras, funcionárias da SMS, encontravam-se lotadas em unidades de atenção primária à saúde e permaneceram vinculadas ao programa por um ano. Lucíola, psicóloga e nutricionista, Helenicy e Ivete são terapeutas ocupacionais. Foram conferidos nomes fictícios às entrevistadas, no sentido de lhes preservar o anonimato.

\section{Estudantes universitários e} preceptores da área da saúde no contexto da atenção básica: os nós e os laços dessas redes de aprendizagem

Em relação aos nós e laços dessas redes de aprendizagem, procuramos escutar de forma sensível estudantes e preceptores da área da saúde, colaboradores desta pesquisa, por meio da análise das suas narrativas, que se encontram dispostas a seguir, de acordo com a inserção de cada um desses sujeitos.

\section{A perspectiva dos estudantes: uma escuta sensivel de suas narrativas}

Uma forma de garantir a vivência interdisciplinar no processo de formação é promover o contato dos estudantes com os serviços de saúde, desde o início da graduação. Neste sentido, aos estudantes do primeiro ao terceiro semestre dos cursos de graduação na área da saúde do DCV/UNEB é ofertado, como componente curricular obrigatório, o Programa de Integração Serviço Saúde Comunidade (PIASC), de caráter multiprofissional e interdisciplinar. O PIASC (I), ofertado no 1o semestre dos Cursos de Graduação, possibilita o conhecimento do território do Distrito Sanitário; o PIASC (II), no 2o semestre, objetiva formar um diagnóstico das condições de saúde no território; e no PIASC (III), ofertado 
no 3 o semestre, busca fazer intervenções que deem conta de contribuir com a solução dos problemas identificados no semestre anterior. Grande parte dos estudantes participantes do PET-Saúde “Doutores Mirins", já tinham cursado os componentes curriculares do PIASC, porém, a inserção no referido projeto ampliou as possibilidades de troca com estudantes de outros cursos de saúde, principalmente em relação às formas de atuação desses profissionais, mesmo que em formação (FONSÊCA; JUNQUEIRA, 2014). Os excertos de narrativas, a seguir, evidenciam a percepção dos estudantes, indicando a interação entre os participantes do programa, de forma positiva:

[...] e também teve a questão de lidar com o outro, eu acho que o PET proporcionou também a questão da interação, tanto com colegas do curso de Fisioterapia, como de outras áreas da saúde. O pessoal de Medicina, de Nutrição, de Fono [audiologia]. Eu descobri também como esses outros profissionais poderiam vir a atuar. (Lúcia, 25/04/16)

Segundo Lacerda e Ribeiro (2007), vivenciar atividades de grupo em projetos de extensão, as quais se propõem a direcionar suas ações para as pessoas, e não para as doenças, reorienta o trabalho do profissional de saúde. Esta vivência interdisciplinar contribui para que os participantes desenvolvam um olhar diferenciado, ampliado, menos restrito à lógica da especialidade, possibilitando uma compreensão maior das questões de saúde da coletividade e das práticas profissionais, havendo, dessa forma, um aumento do interesse, da dedicação e do comprometimento por parte dos envolvidos. Como assinala a estudante do curso de Medicina, os sentidos do fazer profissional e do percurso de formação de cada estudante vão sendo construídos na interação com colegas de áreas diferentes, e isto potencializa as redes de aprendizagem, à medida que os conhecimentos de um influenciam os conhecimentos dos outros e amplificam a compreensão dos cuidados em saúde, de modo integrado.

Com o PET a gente teve um convívio mais intenso. A gente fez amizade com colegas de outros cursos e isso influencia também na sua formação porque você acaba se articulando melhor com pessoas de outros cursos [...] e também a visão do conhecimento do outro, até onde é o meu conhecimento, até onde é o conhecimento do outro, até onde eu alcanço e até onde o outro pode me ajudar também... (Clarisse, 25/04/16)

Percebe-se que a oportunidade do estudante em formação integrar uma equipe do PET-Saúde foi fundamental para todo o processo de formação pessoal e profissional, à medida que possibilitou vivenciar e compartilhar as atividades, os saberes e os espaços da sua profissão, mesmo que em formação, junto aos outros colegas e profissionais de saúde, aos preceptores e demais membros da equipe multiprofissional (FREITAS et al, 2013), configurando as redes de aprendizagem, ao estabelecerem relações entre conhecimentos de diferentes áreas e campos de atuação profissional.

Com o PET a gente acaba tendo mais contato com outros profissionais, outros estudantes [...] esse contato é importante porque no futuro nós vamos trabalhar em equipes multiprofissionais [...] então é importante desde já, desde a formação acadêmica ter esse contato, assim como tivemos contato com profissionais que foram preceptores [de outras áreas]. (Sarah, 29/04/16)

É sabido que, durante a graduação, há o predomínio das práticas individualizadas, principalmente quando os estudantes estão na etapa de formação profissionalizante, conforme proposto pelas matrizes curriculares vigentes. Todo esse processo pode gerar certa dificuldade e/ou expectativa, quando da inserção desse estudante no mundo do trabalho (VASCONCELOS, 2011). Neste sentido, a possibilidade de participar de uma atividade coletiva, com enfoque multiprofissional, interdisciplinar e interprofissional, como propõe o PET- 
Saúde, é uma maneira formidável de garantir a relação com a prática, no processo formativo. Ademais, poder observar, interagir e construir o conceito de trabalho, em equipe, vivenciando as relações interpessoais e possibilitando a construção de uma visão complexa da área de saúde e seus diferentes campos de atuação profissional. (FONSÊCA; JUNQUEIRA, 2014; MADRUGA et al, 2015).

A participação em programas como o PET-Saúde possibilita uma relação de ensino e aprendizagem pautada na atenção à saúde da população, e, ao estudante, possibilita verificar situações reais, vivenciadas por equipes de saúde em um serviço e/ou comunidade (FONSÊCA; JUNQUEIRA, 2014). Como assinala a estudante de Medicina, "a gente teve um contato mais aprofundado com a atenção básica, com os profissionais da atenção básica, com os problemas, as dificuldades e também com os sucessos...".

O projeto PET-Saúde "Doutores Mirins" foi idealizado em várias etapas, iniciadas pela vivência dos estudantes juntamente aos preceptores em uma Unidade de Saúde. A inserção nos serviços e em outros cenários de práticas, como as escolas participantes do projeto, possibilitou ampliar o conhecimento sobre a qualidade dos serviços, o papel dos profissionais no sistema, e a relação entre a saúde e ensino público, no território onde o projeto foi desenvolvido.

A gente passou um tempo no posto [USF] e deu para entender [...] a dinâmica de como funciona e você, logo no segundo, terceiro semestre, você já está dentro de um posto, você tem uma visão totalmente diferente, você entende as falhas, você percebe a força de vontade do pessoal, mesmo com todas as falhas do sistema que há [...] não é um sistema perfeito, mas ainda assim tem pessoas que se esforçam para aquilo funcionar. (Sarah, 29/04/16)

Como proposto, o PET-Saúde é um indutor de melhorias, tanto para os serviços quanto para os estudantes, que podem projetar uma possivel atuação profissional no cenário das práticas, deixando-os mais preparados para futuras demandas da comunidade/população (FONSÊCA; JUNQUEIRA, 2014; FREITAS et al, 2013; BRASIL, 2008. A articulação ensino-serviço é pautada pelo PET-Saúde e reconhecida pelos estudantes como oportunidade de ampliação e troca de saberes e de experiências que ultrapassam as proporcionadas pelo ambiente universitário. Tais iniciativas possibilitam o aprendizado para além dos conceitos teóricos (MADRUGA et al, 2015).

Os estudantes reconhecem a inserção nos cenários de prática como uma oportunidade bastante desafiadora, quando se remetem às relações interpessoais com a equipe multiprofissional e interdisciplinar, permitindo uma reflexão de onde e como atuar no contexto da saúde pública, quando da sua inserção no mundo do trabalho. Segundo Araújo e Rocha (2007), o trabalho interdisciplinar em saúde desdobra-se na interação entre diferentes atores sociais, o que pressupõe uma relação recíproca de comunicação e articulação entre seus componentes, para assegurar a atenção integral e atender as necessidades de saúde da comunidade.

No futuro nós vamos trabalhar com vários tipos de pessoas e assim o trabalho em equipe [...] é algo que você tem que aprender a lidar com cada tipo de pessoa, com cada componente da equipe [...] então é essa questão de flexibilizar, de tentar entender o outro, então o PET ajudou bastante neste sentido. (Sarah, 29/04/16)

0 trabalho em equipe é uma modalidade do trabalho coletivo, caracterizado pela relação recíproca entre as dimensões complementares de trabalho e a interação dos membros do grupo (PEDUZZI, 2001). A atuação em equipe pode ser concebida como um recurso para o aumento da produtividade e da racionalização dos serviços (ARAÚJO; ROCHA, 2007). No con- 
texto da integralidade do cuidado em saúde, há uma necessidade do trabalho multiprofissional no cotidiano das Unidades de Saúde, e ressalta-se a importância deste trabalho em equipe, que foi percebido pelos estudantes, para alcançar o objetivo da integralidade (BRAGA et al, 2014).

O PET me ensinou a manter o equilíbrio [...] foram dois anos e meio que eu tive uma evolução incrivel na organização [...] o PET era um grupo organizado que propiciou uma nova dinâmica para a minha vida, eu me tornei mais organizado, mais ciente, e eu acho que isso foi um dos grandes ganhos para mim. (Eduardo, 25/04/16)

Durante todo o projeto vinculado ao PETSaúde "Doutores Mirins", os estudantes foram membros ativos em comissões estratégicas de organização do trabalho da equipe, e isto refletiu não apenas em uma transformação profissional, mas também pessoal. Estes são fatores reconhecidos também como facilitadores dessa transformação: o fortalecimento da relação estudante - docente/tutor e estudante - preceptor. Os estudantes que participaram de projetos de extensão na comunidade percebem as diferenças existentes entre os ambientes formais de ensino e os cenários de prática, e sinalizam o papel do tutor como o de um norteador e motivador do processo ensino -aprendizagem, somando-se às contribuições dos outros atores desse processo (FONSÊCA; JUNQUEIRA, 2014). Destacam, ainda, a importância da relação com os preceptores, que facilitam o processo de aprendizagem e enriquecem de sentido as atividades a serem desenvolvidas. Ademais, a relação com a preceptoria, que neste projeto foi composta por um grupo de profissionais de saúde de nivel superior, agregou valor à formação dos estudantes, à medida que facilitou a interação com a comunidade e suas necessidades. Possibilitou, ainda, o conhecimento do perfil epidemiológico e social da população e o contato com os profissionais do serviço (LIMA; ROZENDO, 2015).

Com o objetivo de planejar as atividades e sistematizar os conhecimentos aprendidos a partir das ações de intervenção do PET-Saúde "Doutores Mirins", foram realizadas além das reuniões semanais, oficinas com outros profissionais que foram agregados ao processo, como consultores ad hoc. Nessas atividades, havia um certo revezamento de papéis e os estudantes, ora assumiam o protagonismo na produção científica do grupo, ora eram mediados por outros profissionais. Em todo o percurso, eram orientados pela tutora do Projeto, para o planejamento das ações, debates, apresentações e reflexões sobre os temas. As primeiras intervenções desenvolvidas na comunidade suscitaram o desenvolvimento de outros projetos, que contribuíram para o aprofundamento do processo educativo na área de saúde (MORAES, 2007), conforme salienta a estudante do Curso de Medicina:

Eu acho que o PET é mais profundo que a Iniciação Científica sem dúvida pela questão da extensão e por serem dois anos de vínculo e isso eu acho que é bem bacana porque você consegue fazer um trabalho a longo prazo [pesquisa e extensão]. (Clarisse, 25/04/16)

A integração ensino-serviço-comunidade revela objetos de pesquisa nos espaços da produção da saúde, gerando conhecimento, tanto para os serviços quanto para a academia, contemplando aspectos sociais (FONSÊCA; JUNQUEIRA, 2014). Como tem sido constatado em outros grupos vinculados a outras Instituições de Ensino Superior, a participação dos estudantes em programas como o Pró-PET-Saúde, possibilita o planejamento e o acompanhamento das ações de intervenção nas unidades de atenção básica. Essas vivências oportunizaram aos estudantes construírem o sentido da profissão, ao compararem as dificuldades e os problemas de saúde da população assistida aos conhecimentos adquiridos em diferentes 
componentes curriculares dos cursos de graduação.

\section{A visão dos preceptores: o que revelam suas narrativas sobre as redes de aprendizagem}

Para o Programa PET-Saúde, o preceptor é o profissional de saúde que atua na rede de serviços da atenção básica e que propicia ao estudante de graduação uma vivência interdisciplinar precoce no contexto do SUS. O preceptor é o elo de ligação entre a academia e o serviço e, ao acolher os estudantes, contribui para a formação dos futuros profissionais para que assumam uma atuação pautada nos princípios da integralidade e da resolubilidade da atenção à saúde. Tem como função, ainda, aconselhar, inspirar, propor reflexões sobre o processo de trabalho e espelhar a prática profissional, priorizando o trabalho em equipe (OLIVEIRA et al, 2012; FONSÊCA; JUNQUEIRA, 2014).

De modo geral, os preceptores são selecionados pelos tutores, professores universitários responsáveis pela mediação das atividades de pesquisa e intervenção, que sabem que o sucesso desse programa reside na boa interação entre todos os envolvidos. Todavia, a aproximação entre preceptores e estudantes gera inquietações para ambos. Para os estudantes, a atuação dos profissionais em serviço suscita reflexões sobre a teoria presente nos componentes curriculares, desmistifica os serviços, aproxima-os do fazer saúde e amplia as suas oportunidades de aprendizagem. Para os preceptores, a vivência com estudantes de graduação, na condição de mediador e facilitador da aprendizagem dos futuros profissionais, coloca em cheque a atualidade dos seus conhecimentos e possibilita refletir sobre as próprias práticas, que, ao longo dos tempos, tendem a se tornar rotineiras e acríticas (FONSÊCA; JUNQUEIRA, 2014).
A experiência de integrar uma equipe do PET é analisada pela preceptora Helenicy, que, no excerto de entrevista, reitera os processos de reflexão sobre sua práxis e o crescimento pessoal e profissional.

Quando surgiu a possibilidade do PET, eu não sabia exatamente o que era. Eu comecei a pesquisar e o que me encantou foi que era um programa de educação que envolvia o trabalho. Então o PET me favoreceu conhecer uma série de coisas que eu não conhecia. Eu aprendi demais com os alunos porque eu tinha que estudar para discutir com eles as atividades, como é que essas coisas aconteceriam, e foi num momento importantíssimo porque eu estava chegando para trabalhar no município e eu não tinha uma vivência prática na atenção primária. (Helenicy, 21/04/16)

O excerto da preceptora deixa escapar que, na relação com os estudantes, a rede de aprendizagem de fato se estabeleceu, pois, mesmo na condição de profissional da saúde, ela se viu diante de grandes oportunidades de aprendizagem, à medida que precisava estudar, para travar um diálogo capaz de articular a teoria que fundamenta as suas atividades profissionais. 0 fato de estar recém-chegada ao serviço de saúde, na Prefeitura, indica a importância da parceria com o PET, para qualificar a sua atuação como preceptora. Na sua avaliação:

O PET [...] foi um divisor de águas na minha vida, me ajudou como profissional a repensar inclusive as minhas práticas. Porque hoje, ainda hoje, um ano e um pouquinho depois que o programa acabou eu me vejo falando coisas e fazendo coisas relacionadas ao PET, então assim [...]. Eu até me emociono porque eu aprendi demais, não só como profissional, mas como pessoa. (Helenicy, 21/04/16)

Mais uma vez, a preceptora reafirma a importância do PET, na construção das redes de aprendizagem, uma vez que, mesmo com a conclusão do Programa, os 
conhecimentos construídos se mantêm vivos na sua prática, além de refletir sobre a sua implicação ao trabalho desenvolvido na atenção básica. Além disso, a presença dos estudantes no contexto dos serviços instigou a preceptora a se atualizar, a desenvolver novas tecnologias leves em saúde e, desta forma, as atividades propostas podem passar a ser mais agradáveis, dinâmicas e criativas, gerando crescimento pessoal e profissional (LIMA; ROZENDO, 2015).

Lima e Rozendo (2015) afirmam que a preceptoria é um espaço que oportuniza a reflexão, a discussão, a construção do conhecimento e a ponderação sobre as ações que serão desenvolvidas no contexto da atenção. A oportunidade de enfrentar os problemas do cotidiano dos serviços, com estudantes e professores das várias áreas de conhecimento em saúde, possibilita não só a reavaliação do fazer usual, como também o desenvolvimento de soluções criativas, de cunho multiprofissional. Todavia, é preciso que o preceptor seja permeável, tendo em vista modificar suas práticas e desta forma alterar o ambiente de trabalho, ressignificar o fazer e influenciar os profissionais a agirem da mesma forma. 0 excerto de narrativa da preceptora Ivete reforça estes aspectos, ao incorporar mudanças no enfoque do cuidado em saúde, ampliando o espectro da atenção para todos os usuários.

Eu não tenho dúvidas que a experiência do PET foi muito importante para a prática, até para gente pensar que atenção básica reordena o fluxo de cuidado no sistema de saúde. Então é parar com essa ideia de falar só da doença, falar da doença através da saúde né, porquê é a ideia, mas não é o que acontece, as ações prioritárias são exigidas e que tem que ser cumpridas acabam focando muito na doença, $e$ esquecendo de oficinas práticas tão legais de empoderamento, de multiplicadores [...]. (Ivete, 16/03/16)

Para esta preceptora, a articulação de teoria e prática, principal pressuposto do Projeto "Doutores Mirins", é fundamental para a mudança de sentido em relação ao cuidado e à assistência à saúde, à medida que, por meio de oficinas, os sujeitos são instigados a pensar formas de como ter uma boa saúde e não como evitar doenças. A mudança de enfoque metodológico, por meio de oficinas que enfatizam a prática de saúde, na opinião da preceptora, contribuiu para o empoderamento, tanto dos estudantes quanto dos profissionais de saúde. Para ela:

O PET agregou valores para a minha prática na atenção básica [...] lidar com o público que teoricamente não tinha [a doença] foi extremamente importante [...] nas ações do posto a gente pôde pensar assim, olha porque só chamar os hipertensos e os diabéticos, né? Vamos chamar também todo mundo, né? (Ivete, 16/03/16)

As afirmações da preceptora Ivete reforçam que o PET contribuiu com a aprendizagem e incitou mudanças nas formas de atuar. Ressaltase o fato de que muitos dos profissionais que estão atuando nos serviços foram formados para desempenhar seus papéis, em uma lógica anterior à do SUS, ou seja, formados antes da adequação das Diretrizes Curriculares Nacionais dos cursos de graduação ao SUS, que ocorreram em 2001 (LIMA; ROZENDO, 2015). Antes da criação do SUS, os procedimentos eram predominantemente curativos, individualizados e centrados na figura do médico.

$\mathrm{Na}$ lógica da atuação que contempla a Reforma Sanitária Brasileira e na Lei Orgânica da Saúde, o modelo de atenção é chamado de Vigilância à Saúde (BRASIL, 1990). Este modelo 
está pautado na efetivação da integralidade do cuidado, na efetividade e equidade, atuando sobre os danos (agravos, doenças, acidentes), os riscos (fatores individuais, coletivos e socioambientais) e determinantes (socioestruturais) do processo saúde-doença, e no desenvolvimento de ações intersetoriais para a reorganização das práticas de saúde em nivel local.

[...] Então o PET me ajudou muito a repensar inclusive, não nas formas de atuar, para além da assistência clínica, mas ações de educação em saúde, promoção de saúde, reconhecer as possibilidades desses usuários que chegam [...]. Têm histórias que justificam muitas vezes a não adesão ao tratamento, a não compreensão do que a gente propõe como profissional de saúde. E o PET, auxiliou nesse processo de [...] de me aproximar dessa comunidade que eu atendo [...], usando metodologias que a gente usava lá [...]. (Helenicy, 21/03/16)

Foi oportuno para a gente avançar nessa proposta que deveria ser já muito comum na atenção básica, né? Que é produção de cuidado, atenção do cuidado. Depois da experiência do PET a gente pode trazer uma proposta para 0 grupo do Hiperdia não só as pessoas com Hipertensão e Diabetes, que é a forma tradicional, mas trazer também a comunidade que é de risco. (Ivete, 16/03/16)

O que o PET deixou para mim foi essa ludicidade, principalmente trabalhar mais com uma forma mais efetiva, né? Essa forma de trabalhar muda o comportamento da família das pessoas... um caminho mais confortável de mudança. (Lucíola, 19.03.16)

Sob a lógica das preceptoras, os serviços são orientados, fundamentalmente, para o atendimento às necessidades de saúde e devem contemplar, portanto, a formação de grupos para ações de educação em saúde, além da centralidade na família, na longitudinalidade dos cuidados e na humanização da atenção. Esta acepção é reiterada nas narrativas, como bem assinalaram as preceptoras.

\section{Considerações finais}

A vantagem das redes de aprendizagem, promovidas a partir da participação dos estudantes e preceptores no PET-Saúde, está na possibilidade de ampliação das trocas e das interações sociais, no desenvolvimento da criatividade, da inclusão da ludicidade como elemento mediador nas práticas de atenção básica. As redes de aprendizagem construídas pelos diferentes sujeitos favoreceram a produção de novos significados em torno da atenção básica, sendo esses suscitados pela articulação entre teoria e prática. No PET-Saúde, estudantes e preceptores revezaram o lugar de ensinar e de aprender. Ao tecer as redes de aprendizagem, os sentimentos de isolamento e receio da crítica deram lugar ao aumento da autoconfiança, da elevação da autoestima e da integração no grupo, fortalecendo o sentimento de solidariedade e respeito mútuo.

Estas reflexões convergem para o entendimento de que exercer a preceptoria neste referido projeto PET-Saúde "Doutores Mirins" contribuiu para a integração ensino-serviço, propiciando a atualização dos profissionais em serviço, o crescimento pessoal e profissional e a aprendizagem para um fazer saúde mais comprometido com os princípios do SUS.

Com o PET-Saúde, a UNEB cumpriu o compromisso de formar profissionais para o atendimento às necessidades de saúde da comunidade, refletindo sobre as atividades desenvolvidas para o enfrentamento de problemas concretos vivenciados a partir de uma rede de aprendizagem, que envolveu estudantes, professores e usuários do sistema de saúde. Com isso, a Universidade reitera a sua responsabilidade social, ao inserir estudantes de graduação em práticas educativas de saúde, pautadas na perspectiva da participação popular, para contribuir com o desenvolvimento do senso crítico e buscar soluções para problemas que emergem de suas vidas. 


\section{Referências}

AMORIM, Marília. A contribuição de Mikhail Bakhtin: a tripla articulação ética, estética e epistemológica. In: FREITAS, Maria Teresa; JOBIM, Solange; KRAMER, Sônia. Ciências humanas e pesquisa: leitura de Mikhail Bakhtin. São Paulo: Cortez, 2003. p. 11-26.

ARAÚJO, Marize Barros de Souza; ROCHA, Paulo de Medeiros. Trabalho em equipe: um desafio para a consolidação da Estratégia de Saúde da Família. Ciênc. Saúde Coletiva, v. 12, n. 2, p. 455-464, 2007.

BARRETO, Ivana Cristina de Holanda Cunha et al. Educação em saúde e intervenções comunitárias. In: DUNCAN, Bruce B.; SCHMIDT, Maria Inês; GIUGLIANI, Elsa R. J.; DUNCAN, Michael Schmidt; GIUGLIANI, Camila. (Orgs.). Medicina ambulatorial. 4. ed. Porto Alegre: Artmed, 2013. p. 98-106.

BERTAUX, Daniel. Narrativas de vida: a pesquisa e seus métodos. Tradução de Zuleide Alves Cardoso Cavalcante e Denise Maria Gurgel Lavallée. 2. ed. São Paulo: Paulus, 2010.

BRAGA, Cristiane Costa et al. Educação permanente para o enfrentamento das doenças crônicas não transmissiveis (DCNT). Rev Bras Ciências Saúde, v. 18, sup. 1, p. 39-44, 2014.

BRASIL. Programa Nacional de Reorientação da Formação Profissional em Saúde (Pró - Saúde). Brasília, DF: Ministério da Saúde; Secretaria de Gestão do Trabalho e da Educação na Saúde, 2009. Disponivel em: <http://prosaude.org/not/prosaude -maio2009/proSaude.pdf. 2009>. Acesso em: 14 mar. 2016.

BRASIL. Portaria Interministerial no 1.802, de 26 de agosto de 2008. Institui o Programa de Educação pelo Trabalho para a Saúde - PET-Saúde. Brasília, DF: Ministério da Saúde, 2008. Disponivel em: <http://bvsms.saude.gov.br/bvs/saudelegis/ gm/2008/pri1802 2608 2008.html. 2008>.

BRASIL. Lei n. 8.080, de 19 de setembro. Dispõe sobre as condições para a promoção, proteção e recuperação da saúde, a organização e o funcionamento dos serviços correspondentes, e dá outras providências. Diário Oficial da União, Brasília, DF, 20 set. 1990. p. 18055.
CARNEIRO Angélica Cotta Lobo Leite et al. Educação para a promoção da saúde no contexto da atenção primária. Rev Panam Salud Publica, Washington, v. 31, n. 2, p. 115-120, feb. 2012.

CARRETEIRO, Teresa Cristina. Fazer de uma coletividade uma história coletiva. In: TAKEUTI, Missae; NIEWIADOMSKI, Christophe. (Orgs.). Reinvenções do sujeito social: teorias e práticas biográficas. Porto Alegre: Sulina, 2009. p. 126-140.

COSTA, Miguel; LÓPEZ, Ernesto. Educación para la salud. Madrid: Pirámide, 1996.

CRUZ, Pedro José Santos Carneiro. Extensão popular: a reinvenção da universidade. In: VASCONCELOS, Eymard Mourão; CRUZ, Pedro José Santos Carneiro. Educação popular na formação universitária. São Paulo: HUCITEC; João Pessoa: Editora Universitária UFPB, 2011. p. 40-61.

DUNCAN, Bruce Bartholow et al. Doenças crônicas não transmissiveis no Brasil: prioridade para enfrentamento e investigação. Rev. Saúde Pública, São Paulo, v. 46, supl. 1, p. 126- 134, dez. 2012.

FONSÊCA, Graciela Soares; JUNQUEIRA, Simone Rennó. Programa de educação pelo trabalho para a saúde - ressignificando a formação dos profissionais de saúde. Curitiba: Editora Appris, 2014.

FREITAS, Paula Hübner et al. Repercussões do PETSaúde na formação de estudantes da área da saúde. Esc. Anna Nery (impr.), v. 17, n. 3, p. 496-504, jul./ set. 2013.

GUEDES, Maria Vilani Cavalcante et al. Barreiras ao tratamento da hipertensão arterial. Rev. bras. enferm., Brasília, v. 64, n. 6, p. 1038- 1042, dez. 2011.

JOVCHELOVITCH, Sandra; BAUER, Martin W. Entrevista Narrativa. In: BAUER, Martin W.; GASKELL, George. Pesquisa qualitativa com texto, imagem e som: um manual prático. Tradução de Pedrinho Guareschi. 6. ed. Petrópolis, RJ: Vozes, 2007. p. 90-113.

LACERDA, Dailton Alencar Lucas de; RIBEIRO, Katia Suely Queiroz Silva. O projeto Fisioterapia na Comunidade e sua interação com o Programa de Ação Interdisciplinar para o Desenvolvimento Social e 
Atenção à Saúde na Comunidade Maria de Nazaré. In: PADILHA, Wilton Wilney Nascimento. (Org.). Relatos e vivências de educação popular. Joao Pessoa: Ideia, 2007. p. 29-40. (Serie Extensão).

LIMA, Patrícia Acioli de Barros; ROZENDO, Célia Alves. Desafios e possibilidades no exercício da preceptoria do Pró-PET-Saúde. Interface: Comunicação, Saúde Educação, Botucatu, v. 19, Supl 1, p. 779-791, 2015.

MADRUGA, Luciana Margarida de Santana et al. O PET-Saúde da Família e a formação de profissionais da saúde: a percepção de estudantes. Interface: Comunicação, Saúde Educação, Botucatu, v. 19, Supl. 1, p. 805-816, 2015.

MORAES, Suzyanne Araújo. O projeto educação popular e atenção a saúde da família. In: PADILHA, Wilton Wilney Nascimento. (Org.). Relatos e vivências de educação popular. Serie Extensão. Joao Pessoa: Ideia, 2007. p. 21-28.

OLIVEIRA, Milca Lopes de et al. PET-Saúde: (in)formar e fazer como processo de aprendizagem em serviços de saúde. Revista Brasileira De Educação Médica, v. 36, n. 1, Supl. 2, p. 105 - 111, 2012.

PAIVA Daniela Cristina Profitti et al. Avaliação da assistência ao paciente com diabetes e/ou hipertensão pelo Programa Saúde da Família do Município de Francisco Morato, São Paulo, Brasil. Cad. Saúde Pública, Rio de Janeiro, v. 22, n. 2, p. 377-385, fev. 2006.

PEDUZZI, Marina. Equipe multiprofissional de saúde: conceito e tipologia. Rev. Saúde Pública, São Paulo, v. 35, n. 1, p. 103-109, fev. 2001.
PINHO, Ana Sueli Teixeira de. 0 tempo escolar e o encontro com o Outro: do ritmo à simultaneidade. 2012. 274 f. Tese (Doutorado em Educação e Contemporaneidade) - Departamento de Educação, Universidade do Estado da Bahia, Salvador, 2012.

RHÉAUME, Jacques. Relato de vida coletivo e empoderamento. In: TAKEUTI, Norma Missae; NIEWIADOMSKI, Christophe. (Orgs.). Reinvenções do sujeito social: teorias e práticas biográficas. Porto Alegre: Sulina, 2009. p. 166-188.

SOUZA, Elizeu Clementino de. Pesquisa narrativa e escrita (auto)biográfica: interfaces metodológicas e formativas. In: SOUZA, Elizeu Clementino; ABRAHÃO, Maria Helena Menna Barreto. (Orgs.). Tempos, narrativas e ficções: a invenção de si. Porto Alegre: EDIPUCRS, 2006. p. 135-147.

TOSCANO, Cristiana et al. Initial impact and cost of a nationwide population screening campaign for diabetes in Brazil: A follow up study. BMC Health Serv. Res., v. 8, n. 189, p. 1-10, sept. 2008.

VASCONCELOS, Eymard Mourão. Educação popular e o movimento de transformação da formação universitária no campo da saúde. In: VASCONCELOS, Eymard Mourão; CRUZ, Pedro José Santos Carneiro. (Orgs.). Educação popular na formação universitária: reflexões com base em uma experiência. São Paulo: Hucitec; João Pessoa: Editora Universitária da UFPB, 2011. p. 362-395.

Recebido em: 14.09.2016

Aprovado em: 15.11 .2016

Helena Fraga-Maia é professora Adjunta da Universidade do Estado da Bahia. Doutora em Saúde Pública. Líder do Grupo de Pesquisa Educação e Saúde. e-mail: helenafragamaia@gmail.com.

Rua Artesão João Prata, 267, Ap. 802, Edf. Maurice Ravel, Itaigara, Salvador, Bahia. CEP 40.150-210.

Ana Sueli Teixeira Pinho é doutora em Educação pelo PPGEduC/UNEB. Professora da Universidade Católica do Salvador. Assessora Pedagógica no Instituto Anísio Teixeira - IAT. Líder do Grupo de Pesquisa Docência e Gestão em Educação e pesquisadora do Grupo de Pesquisa (Auto)biografia, Formação e História Oral (GRAFHO/UNEB). e-mail: ana.pinho@ucsal.br.

Avenida Professor Manoel Ribeiro, 1315, Condomínio Boulevard Iguatemi Jardim, Ap. 904, STIEP. Salvador-Bahia. CEP 41.750-160.

Fernanda Warken Rosa Camelier é professora Titular da Universidade do Estado da Bahia. Doutora em Ciências da Reabilitação. Pesquisadora do Grupo de Pesquisa Educação e Saúde. e-mail: fwrcamelier@gmail.com.

Avenida Silveira Martins, no 2555, Departamento de Ciências da Vida/UNEB, Campus I, Salvador, Bahia. 